\title{
Human Attributes in the Modelling of Work Teams
}

\author{
Juan Martínez-Miranda and Juan Pavón \\ Facultad de Informática, Universidad Complutense Madrid \\ Ciudad Universitaria s/n \\ 28040 Madrid, Spain \\ jmartinez@microart.cat, jpavon@fdi.ucm.es
}

\begin{abstract}
This paper presents a summary of relevant research findings that have been used as the theoretical background in the design of an agent-based model to simulate the human behaviour within work teams (the TEAKS model). It underlines some of the main trends in the modelling of human behaviour in teams, and the rationale for selecting the attributes to represent real team candidates as software agents in the TEAKS model.
\end{abstract}

\section{Introduction}

Computer simulations to analyse and understand complex phenomena have been applied in several research disciplines including Automation [1], Economics [2], Social Sciences [3] and Environmental Sciences [4]. The success in the use of simulations within these research areas relies on the feasibility to play with the behaviour of the modelled phenomenon under study by changing the conditions of its environment and its internal parameters to observe the consequences in a controlled experiment.

The study of human behaviour under specific contexts and circumstances has been one of these complex phenomena under study since early 70's [5]. Over the past few decades, tools and techniques for modelling and predicting human performance in complex systems have evolved and matured, for instance, considering task network models [6] and situational awareness models [7], among others.

In the last years, agent-based modelling has emerged as a relative new technique to model social behaviour, particularly helpful for the modelling of individuals immerse in a social environment such as groups, organisations or societies. The key characteristic of agent-based models is the concept of Agent, which is an autonomous software entity with the ability to interact with other agents and with the environment. Autonomy means that agents are active entities that can take their own decisions. This is not the same with objects, as they are predetermined to perform the operations that someone else requests them. An agent, however, will decide whether to perform or not a requested operation, taking into account its goals and priorities, as well as the context it knows. In this sense, the agent paradigm assimilates quite well the individual in a social system.

This paper presents a summary of relevant research findings that have been used as the theoretical background in the design of an agent-based model to simulate the 
human behaviour within work teams, which has been implemented as the TEAKS model [8]. It first underlines some of the main current trends in the modelling of human behaviour in teams. Then, it focus on explaining the rationale behind the selection of the human attributes that have been included in the TEAKS model to represent real team candidates as software agents.

\section{Modelling Human Behaviour in Work Teams}

The modelling of human behaviour is a great challenge due to the instability, unpredictability and the ability to perform independent actions of human nature. Nevertheless, in the recent years several models and techniques have emerged that clearly indicate that some contextual-limited modelling of human-like behaviours are possible such as in training and learning [8], and for the representation of crisis and emergency situations [9], among others.

An interesting scenario where models of human behaviour are applied is for the analysis and understanding of the different dynamics that take place within groups and teams under specific context. Some examples of works where group behaviours are analysed using agent-based models include the presented in [10], which analyses the behaviour of a group of agents facing the management of common pool resources. Also, [11] report the analysis of the performance in military combatants, studying the effect on their behaviour of individual and social factors. The analysis of a group's behaviour and dynamics when facing the adoption of a new software application is other application described in [12].

One type of teams particularly interesting is the one formed by people in front of their daily activities at work to perform a set of tasks. The analysis of the behaviour and performance of these work teams can support the decision making process of managers to select the right persons to form better work teams taking into account the fact that a group of people with optimal individual abilities may perform suboptimally acting as a work team [13]. From a research point of view, this scenario offers several dimensions to be studied given that the work team's performance is influenced not only by the personal expertise and responsibilities of each team member, but also by some personal characteristics that influence individual, and in consequence, team performance [14].

In this context we have developed TEAKS (TEAm Knowledge-based Structuring), an agent-based model where a virtual team can be configured using the characteristics of the real candidates to form a team of software agents, and given a set of tasks, the model generates statistical information about the possible performance of the agents obtained from the interaction between all the team members and with their assigned tasks [8].

The representation of the real candidates through software agents required a careful study about the individual (internal) attributes to model in the software agents. It is difficult to include all the internal human attributes that affect, influence and direct the behaviour of a person. The most common strategy to follow is to select only those attributes that are important in the context of the phenomenon that will be studied. In this sense, the next section presents a brief review of existent research that indicates the importance of some specific internal attributes in human behaviour, in the context 
of human behaviour at work and within work teams. Additionally, a brief review of some existent artificial systems and architectures that implement the identified attributes are mentioned.

\section{Individual Attributes in the Modelling of Human Behaviour}

A key set of human attributes that influence and direct behaviour within work teams were identified and included in the TEAKS model. Four human attributes were selected and implemented in the model: creativity, emotions, personality traits and trust.

\subsection{Creativity}

The research discipline that traditionally has focused on the study of human behaviour is the Psychology. The psychological cognitive approach focuses on how humans think with the belief that such thought processes affect the way in which humans behave. The interest and development of this psychological approach has been increased from the 1960s originating the Cognitive Science.

According to [15], the central hypothesis of cognitive science is that thinking can best be understood in terms of representational structures in the mind and computational procedures that operate on those structures, i.e. the ComputationalRepresentational Understanding of Mind. The mental processes that are studied in cognitive science include comprehension, inference, decision-making, planning and learning. All these mental processes produce at the end an intelligent human behaviour with the capabilities to develop highly routine tasks to extremely difficult, openended problems.

In the context of human behaviour at work, several studies along the years have proved the high influence of the cognitive abilities on work performance across different types of jobs [16]. One particular outcome originated from the different mental processes that has been deeply studied in the analysis of work performance is the creative behaviour [17]. Research has linked five specific cognitive abilities that influence creativity: problem framing, divergent thinking, mental transformations, practice with alternative solutions, and evaluative ability. The concept of creativity has received much attention (mainly in the Organisational Psychology and Human Resources disciplines) due that it is considered the basic ingredient to be innovative [18], which in turn is a key factor to increase the success in the work performance of an individual, group or organisation.

Moreover, the cognitive and creativity research topics have not remained to exclusively understand work behaviour and/or performance at individual level, but both have been extended to cover the understanding and improvement of behaviour in work teams. In concrete, the term team cognition has been linked to effective team performance and it includes knowledge about team members, task-specific information, and team processes [19]. Team cognition has been also attracted the attention of researchers on creativity to analyse and better understand the creative processes and outcomes that take place at group/team level [20]. 


\subsection{Emotional Behaviour}

In the past, for many years the main belief was that emotions are an undesirable product of the human rational mind, and thus the less emotional a person was, the more intelligent and reasonable the person was. Nevertheless, in recent years some researchers have proved that emotions are a relevant part of the human reasoning and necessary for an intelligent behaviour [21].

In the context of human behaviour at work, the influence of emotions is also recognised of great importance. The clearest example of this importance is the development of the relatively new concept of Emotional Intelligence. According to [22], Emotional Intelligence is composed of four abilities: (1) the ability to identify one's own and others' emotions to accurately express own emotions to others; (2) understanding how emotions orient people toward important information and how different emotional states can induce varying approaches to problem solving; (3) understanding the meaning, progressions, and complexity among emotions; and (4) the ability to stay open to feelings, to detach, and to manage one's own and others' emotions promoting emotional and intellectual growth.

With regard to the influence of emotions within work teams performance, despite the fact that group researchers have long acknowledged the importance of group's emotional life in its performance, there is relatively little research to date. Most of the studies have focused on individual level issues to show a positive relationship between emotional expression and organisational commitment [23]; a positive relationship between emotions and work motivation [24] and the different types of emotions that can be experienced at work [25]. Some others have concentrated efforts on evaluate the effects of mood (different than emotions) into work team performance [26]; and only few studies have reported how emotions influence directly (e.g. envy in work teams [27]) or indirectly (e.g. analysing the role of emotions in conflict management within work teams [28]) the work team performance.

From the existent psychological theories of emotions, the cognitive appraisal theories focus on the elicitation of emotional experiences as result from constant evaluations of the subjective significance of construed situations and events, according to specific dimensions or criteria [29]. The key characteristic of these theories is that the emotional process is seen as the permanent assessment of the environment according to the person's goals, intentions and standards, i.e. appraisal. Due that cognitive appraisal theories are focused on emotion as a process rather than in the descriptive characterisations of emotions in dimensional or categorical models, several works in modelling human behaviour are based on these theories. One of the most influential theories for implementation in artificial systems has been the often referred as the OCC model [30]. In summary, the OCC model relates types of emotional reactions to types of emotional responses. An individual can have positive or negative reactions to a specific situation depending on how the object of the appraisal (an event, and action of somebody or an actual object) is relevant to the individual's goals, to the standards it tries to uphold, or to its tastes. The OCC model is used as the theoretical basis in several applications, and more deeply referred to model an intelligent and believable behaviour in synthetic characters [31].

The above mentioned theories, studies, and implementation works are only small evidence about the increasing interest in the study and modelling of emotions, a deeper analysis can be found in [32]. It is clear the high importance that the emotional 
behaviour has on the global human behaviour and the modelling of it in artificial systems has originated great efforts such as the development of new research branches (e.g. Affective Computing [33]) and large research associations (e.g. HUMAINE: http://emotion-research.net/).

\subsection{Personality Traits}

Another branch of the Psychology that has dedicated efforts, since long time ago, to the study of human behaviour based on the identification and classification of individual differences is Personality Psychology [34]. Due to the development of different theories of personality, there is not an achieved consensus about the definition of the concept, but the different definitions of personality have some common features. In [34], three main features are proposed: $i)$ uniqueness of the individual: each person is different; ii) uniformity of behaviour: behaviour of the individual is consistent over time and across situations; iv) Content and processes: personality consists of something that influences behaviour, e.g. how our expectations in one situation influence our behaviour in others?

The different theories of personality have originated also different models containing various dimensions to assess the distinct (but consistent) styles of behaviour. In 1923 Carl Jung [35] proposed two types of attitudes in people: extraversion and introversion which modify four Jung's proposed functions of consciousness: perceiving (Sensation and Intuition) and judging (Thinking and Feeling). Other model of personality was proposed by Hans Eysenck [36] based on the biological perspective of personality. The Eysenck's model, known as the P-E-N model, initially includes two dimensions of personality: extraversion and neuroticism, adding afterwards the third psychoticism dimension.

Probably the most accepted (but not exempt of criticism) personality model is the known as the Big Five model [37]. The five big factors of personality, also known as the OCEAN model, include Openness, Conscientiousness, Extroversion, Agreeableness and Neuroticism.

In the context of human behaviour at work, one of the studies that have focused on the identification of the personal styles that affect the job performance and relationships is the presented in [38], where four styles of behaviour were found represented in any occupation. The four proposed patterns of behaviour at work are Amiable: the Relationship specialist; Analytical: the Technical specialist; Driver: the Command specialist; and Expressive: the Social specialist.

Regarding the influence of the personality traits within work teams, several studies have been developed to relate the different traits of personality with the team performance. A study developed with an engineering team found that team members who possess high level of conscientiousness manifested increased task performance, while those with minimum composite level of extraversion are highly successful in managing product design processes [39]. More recently, a different study was developed using 78 college students working in 10 long-standing teams competing in a business simulation, finding that emotional stability (the opposite trait of neuroticism) predicted task performance and agreeableness predicted cohesion within the work team [40].

It can be argued that the results obtained from the different studies largely depend on the types of activities of each work team, but it is unquestionable that the 
personality traits are another important factor that directs the behaviour of a person. Due to this fact, the interest to include models of personality into artificial systems has been increased in the last years (just as same as the emotions) to reproduce more realistic human behaviours. In the development of synthetic characters (more commonly known as virtual characters) different theories of personality psychology are applied to direct the behaviour of these artificial entities. Virtual characters with personality have been used for pedagogical purposes [41], the simulation of bargaining in e-commerce [42] and entertainment [43] among some others.

\subsection{Trust}

Additional relevant factors that directly affect human behaviour are the actions and behaviours of the other people whom the individual is interacting in its same environment. This is especially important when talking about work teams due to the importance that human relations have to achieve team-working behaviours (such as good communication and co-ordination among the team members) and are the foundation of healthy and productive work environments [44].

An important factor that contributes to create and maintain the productive work environments is the concept of trust. The increasing interest in trust within organisations could be explained as there are more and more large companies and consortiums where several people need to work together from different geographically locations. New theories and hypotheses about the thinking and functioning of organisations have been replacing traditional aspects of management by collaborative approaches emphasising ideas of coordination, sharing of responsibilities and risk taking [45]. More recently, and with the great development of applications in Internet, the interest in the study of trust has grown up and some research works put efforts towards the modelling of trust and reputation concepts addressed mainly to e-Commerce applications. Most of these models of trust and reputation use software agents as the entities where the relationship of trust takes place and is represented using specific characteristics of each model [46]. Some other models and studies have been developed in the Human Resources and Management disciplines to analyse the importance of trust within work teams and how it is related with performance effectiveness [47].

\section{Conclusions}

All the studies presented in this paper show the relevance of different individual attributes in the generation of human behaviour. Even that the selected set of attributes is not, of course, the complete spectrum that produces, influences and directs the human behaviour, it is at least, an important part of the complete picture and allows the study and understanding of work team dynamics.

\section{Acknowledgments}

This work has been done in the context of the project Agent-based Modelling and Simulation of Complex Social Systems (SiCoSSys), supported by Spanish Council for Science and Innovation, with grant TIN2008-06464-C03-01. 


\section{References}

1. Gupta, R.P., Srivastava, S.C.: A distribution automation system Simulator for training and research. International Journal of Electrical Engineering Education 45(4), 336-355 (2008)

2. Marks, R.E.: Validating Simulation Models: A General Framework and Four Applied Examples. Computational Economics 30(3), 265-290 (2007)

3. Gilbert, N., Troitzsch, K.G.: Simulation for the Social Scientist. Open University Press, Stony Stratford (2005)

4. Gernaey, K.V., van Loosdrecht, M.C.M., Henze, M., Lind, M., Jørgensen, S.B.: Activated sludge wastewater treatment plant modeling and simulation: state of the art. Environmental Modelling and Software 9(9), 763-783 (2004)

5. Dutton, J.M., Starbuck, W.H.: Computer Simulation of Human Behaviour. John Willey, New York (1971)

6. Wetteland, C.R., Miller, J.L., French, J., O’Brian, K., Spooner, D.J.: The Human Simulation: Resolving Manning Issues Onboard DD21. In: Proc. of the 2000 Winter Simulation Conference (2000)

7. Sawaragi, T., Murasawa, K.: Simulating behaviours of human situation awareness under high workloads. Artificial Intelligence in Engineering 15(4), 365-381 (2001)

8. Martínez-Miranda, J., Pavón, J.: An Agent-Based Simulation Tool to Support Work Teams Formation. Advances in Soft Computing 50(2009), 80-89 (2008)

9. Kozine, I.: Simulation of human performance in time-pressured scenarios. Proc. of the Institution of Mechanical Engineers, Part O: Journal of Risk and Reliability 221(2), 141-151 (2007)

10. Pahl-Wost, C., Ebenhöh, E.: Heuristics to characterise human behaviour in agent based models. In: Proc. of iEMSs 2004 Int. Congress: Complexity and Integrated Resources Management (June 2004)

11. Luscombe, R., Mitchard, H.: Exploring Simple Human Behaviour Representation Using Agent Based Distillations. In: Proceedings of SimTecT 2003, Adelaide, Australia, May 2629 (2003)

12. $\mathrm{Wu}, \mathrm{J} ., \mathrm{Hu}, \mathrm{B} .:$ Modeling and simulation of group behavior in E-Government implementation. In: Henderson, et al. (eds.) Proc. of the 2007 Winter Simulation Conference, Washington (2007)

13. Steiner, I.D.: Group process and productivity. Academic Press, New York (1972)

14. Morgeson, F.P., Reider, M.H., Campion, M.A.: Selecting Individuals in Team Settings: The Importance of Social Skills, Personality Characteristics and Teamwork Knowledge. Personnel Psychology 58(3), 583-611 (2005)

15. Thagard, P.: Mind: Introduction to Cognitive Science, 2nd edn. MIT Press, Cambridge

16. Zyphur, M.J., Bradley, J.C., Landis, R.S., Thoresen, C.J.: The Effects of Cognitive Ability and Conscientiousness on Performance Over Time: A Censored Latent Growth Model. Human Performance 21(1), 1-27 (2008)

17. Gilson, L.: Why be Creative. A Review of the Practical Outcomes Associated With Creativity at the Individual, Group, and Organizational Levels. In: Shalley, C., Zou, J. (eds.) Handbook of Organizational Creativity, pp. 303-322. Lawrence Erlbaum Associates, Mahwah (2008)

18. Shalley, C.E., Zhou, J.: Organizational Creativity Research. A Historical Overview. In: Shalley, C., Zou, J. (eds.) Handbook of Organizational Creativity, pp. 3-31. Lawrence Erlbaum Associates, Mahwah (2008) 
19. Fiore, S.M., Salas, E.: Why we need team cognition. In: Salas, E., Fiore, S.M. (eds.) Team Cognition: Understanding the Factors that Drive Process and Performance, pp. 235-248. American Psychological Association, Washington (2004)

20. Paulus, P.B., Nijstad, B.A.: Group Creativity: Innovation through collaboration. Oxford University Press, New York (2003)

21. Gray, J., Braver, T., Raichele, M.: Integration of Emotion and Cognition in the Lateral Prefrontal Cortex. In: Proceedings of the National Academy of Sciences USA, pp. 4115-4120 (2002)

22. Mayer, J.D., Caruso, D., Salovey, P.: Emotional intelligence meets traditional standards for an intelligence. Intelligence 27, 267-298 (1999)

23. Allen, N.J., Meyer, J.P.: The measurement and antecedents of affective, continuance and normative commitment to the organization. Journal of Occupational Psychology 63, 1-18 (1990)

24. George, J.M., Brief, A.P.: Motivational agendas in the workplace: The effects of feelings on focus of attention and work motivation. Research in Organizational Behavior 18, 75 109 (1996)

25. Rafaeli, A., Sutton, R.I.: The expression of emotion in organizational life. Research in Organizational Behavior 11, 1-42 (1989)

26. Jordan, P.J., Lawrence, S.A.: The impact of negative mood on team performance. Journal of Management \& Organization 12(2), 131-145 (2006)

27. Duffy, M.K., Shaw, J.D.: The Salieri syndrome: Consequences of envy in groups. Small Group Research 31, 3-23 (2000)

28. Desivilya, H.S., Yagil, D.: The Role of Emotions in Conflict Management: The Case of Work Teams. In: IACM 17th Annual Conference Paper, SSRN:

http: / / ssrn.com/abstract $=602041$

29. Scherer, K.R.: Psychological models of emotion. In: Borod, J.C. (ed.) The Neuropsychology of Emotion, pp. 137-162. Oxford University Press, New York (2000)

30. Ortony, A., Clore, G.L., Collins, A.: The Cognitive Structure of Emotions. Cambridge University Press, Cambridge (1988)

31. Taihua, L., Yuhui, Q., Peng, Y., Guoxiang, Z.: Exploiting Model of Personality and Emotion of Learning Companion Agent. In: Int. Conf. on Computer Systems and Applications, pp. 860-865 (2007)

32. Martínez-Miranda, J., Aldea, A.: Emotions in Human and Artificial Intelligence. Computers in Human Behaviour Journal 21(2) (March 2005)

33. Picard, R.W.: Affective Computing. MIT Press, Cambridge (1997)

34. Carducci, B.J.: The Psychology of Personality, 2nd edn. Wiley-Blackwell (2009)

35. Jung, C.G.: Psychological Types. In: Collected Works of C.G. Jung, vol. 6. Princeton University Press, Princeton (August 1, 1971)

36. Eysenck, H.: Dimensions of Personality. Trubner \& Co., Ltd., Kegan Paul (1947)

37. Goldberg, L.R.: The Structure of Phenotypic Personality Traits. American Psychologist 48(1), 26-34 (1993)

38. Merrill, D.W., Reid, R.H.: Personal Styles \& Effective Performance. CRC Press LLC, Boca Raton (1999)

39. Kichuk, S.L., Wiesner, W.H.: The Big Five personality factors and team performance: implications for selecting successful product design teams. Journal of Engineering and Technology Management 14(3), 195-221 (1997)

40. O’Neill, T.A., Kline, T.J.B.: Personality as predictor of teamwork: a business simulator study. North American Journal of Psychology (March 1, 2008) 
41. Martínez-Miranda, J., Jung, B., Payr, S., Petta, P.: The Intermediary Agent's Brain: Supporting Learning to Collaborate at the Inter-Personal Level. In: Proceedings of the 7th Conference on Autonomous Agents and Multiagent Systems AAMAS 2008, vol. 3, pp. 1277-1280 (2008)

42. Nassiri-Mofakham, F., Ghasem-Aghaee, N., Ali Nematbakhsh, M., Baraani-Dastjerdi, A.: A personality-based simulation of bargaining in e-commerce. Simulation Gaming 39(1), 83-100 (2008)

43. Campano, S., Sabouret, N.: A socio-emotional model of impoliteness for non-player characters. In: Proceedings of AAMAS 2009, vol. 2 (2009)

44. Pyoria, P.: Information technology, human relations and knowledge work teams. Team Performance Management 11(3-4), 104-112 (2005)

45. Vangen, S., Huxham, C.: Nurturing Collaborative Relations: Building Trust in Interorganizational Collaboration. J. of App. Behavioral Science 39(1), 5-31 (2003)

46. Sabater, J., Sierra, C.: Review on Computational Trust and Reputation Models. Artificial Intelligence Review 24(1), 33-60 (2005)

47. Costa, A.C.: Work team trust and effectiveness. Personnel Review 32(5), 605-622 (2003) 